\title{
Mixed case and masking interact in word recognition
}

\author{
LARRY HOCHHAUS, ERIC WILLIAMS, and KEVIN POLK \\ Oklahoma State University, Stillwater, Oklahoma
}

\begin{abstract}
The purpose of the present experiment was to determine if mixed letter case (e.g., MiXeD cAsE) and stimulus degradation (masking produced by overprinted backslash characters) interact in a word naming task. A $2 \times 2$ factorial design was used with 26 college students in a list pronunciation format. Both variables had a significant effect on pronunciation time and on errors. Additionally, mixed case and masking interacted in an overadditive fashion on both dependent variable measures. The data were interpreted as support for a model of human information processing in which both mixed case and masking affect the feature-extraction stage of processing.
\end{abstract}

An issue of concern in cognitive psychology is the isolation and identification of stages in information processing. In 1868, Donders proposed that reaction time, the interval between the presentation of a stimulus and the onset of the subject's response, is composed of a series of independent serial stages. Donders developed the $s u b$ traction method to identify these stages and to study stage properties. According to the subtraction method, if one task is comprised of $n$ stages and if a second task is comprised of $n-1$ stages, then the difference between the time required to perform the two tasks represents the duration of the stage that was missing in the second task (Salthouse, 1981). Donders's subtraction method was highly popular until the late 1800 s, when the claim that changing from one task to another implies only addition or deletion of a stage was challenged. The subtraction method subsequently fell into disuse and was nearly abandoned in the early part of this century (see Sanders, 1980, for a fuller review).

It was not until the late 1960 s that the concept of serial stage models again gained popularity. Smith (1968) suggested a stage model consisting of four stages: preprocessing, identification, response choice, and response execution. One year later, Sternberg (1969) introduced the additive factor method as an alternative technique for identifying cognitive processing stages. He proposed that if two variables in a factorial design have a main effect on reaction time, while their effects do not interact, then two separate stages are likely present. However, if the effects interact, that is, if the size of the effect of one variable depends on the other variable, the data suggest that each of the two variables influences a common processing stage. Sternberg's additive factor method helped estab-

This research was partially supported by a grant from the State of Oklahoma to the first author. Requests for reprints should be addressed to Larry Hochhaus, Department of Psychology, Oklahoma State University, Stillwater, OK 74078. lish strong renewed interest in the serial stage theories popular in the last 15 years. For other reviews of stage model concepts and assumptions, see Pachella (1974), Sanders $(1980,1983)$, and Salthouse (1981). For alternatives to the independent serial stages model, see, for example, Eriksen and Schultz (1979), McClelland (1979), or Schweikert (1983).

Sanders (1980) noted that the subtraction method and the additive factor method share several assumptions: (1) reaction time is filled with a sequence of independent stages, (2) each stage produces a constant transformation of information and repeatedly contains the same mental operations, (3) input and output of a stage are independent of stage duration, and (4) the start of each stage must wait for the completion of the prior stage. Reasoning using the additive factor method, Sanders (1980) proposed six stages of information processing in visual symbol recognition: preprocessing, feature extraction, identification, response choice, response programming, and motor adjustment. In the second of Sanders's stages, feature extraction, components of letters such as line segments, intersections, and curves are detected preliminarily to letter recognition. The present research is aimed at further evaluation of the feature-extraction stage.

Prior research (Fisher, 1975) indicates that the effects of mixed-case words on reading speed interact with manipulations of the symbol (usually a blank) inserted between words. The interaction was hyperadditive; that is, the effect of mixed case on reading time was greater when, for example, spaces between words were absent. However, the interaction effect was not present in all of Fisher's experiments. The purpose of the present study was to extend and clarify Fisher's results. Visual masking was used as an alternative to the word spaces manipulation. Visual masking and mixed case were expected to affect the feature-extraction stage of recognition processing; hence, we predicted a hyperadditive interaction from the use of masking and mixed case within a single experimental task. 


\section{METHOD}

\section{Subjects}

Twenty-six undergraduate students enrolled in an experimental psychology course at Oklahoma State University participated in the experiment. The group consisted of an equal number of males and females, and subjects were 20 to 28 years in age.

\section{Materials}

Three blocks of word lists were presented to each subject. Each block consisted of four lists, one for each of the four treatment conditions: capitals-intact, capitals-degraded, mixed case-intact, and mixed case-degraded. The degraded condition was produced by printing a slash over the letters of each word in the masking conditions. The mixedcase condition was produced by alternating upper- and lowercase letters in a word. Because standard print was used, the uppercase letters were larger than the lowercase letters. The first four lists (one of each condition) were used as practice and did not enter the data analysis. A balanced Latin square design was used to control the order of the eight test lists.

Each of the 12 lists consisted of 20 words. The 240 words were taken from Kucera and Francis (1967) and had a mean frequency of 224 per million $(S D=36)$. The pronunciation time for each list was measured using a stopwatch or a wristwatch with a second hand.

\section{Procedure}

The students worked in pairs to collect the data of the experiment using a procedure suggested by Rozen and Jonides (1977). Participants alternated experimenter and subject roles. The subjects were required to read each list aloud from top to bottom and to say "stop" after reading the last word. The subjects were told that pronunciation times and accuracy would both be measured, but that accuracy was the most important of the two measures. Instructions requested subjects to say the word "blank" if they could not read a word. Experimenters counted the number of errors, which were defined to include incorrect words, omissions, or hesitations longer than $1 \mathrm{sec}$. Experimenters recorded the reading time and number of errors for each list. After completing the three blocks of lists, experimenter and subject roles were reversed and the tasks were repeated.

\section{RESULTS}

For both reading speed and errors, the average of Block 2 and Block 3 scores for each combination of conditions was computed. Speed and error scores were evaluated by separate $2 \times 2$ factorial, repeated measures analysis of variance procedures.

Reading speed and error means for each combination of independent variable conditions are shown in Figure 1. Independent variables and their levels were letter case (CAPITALS vs. MiXeD cAsE) and visual quality (intact vs. degraded by backslash). All main effects and interaction effects in each analysis were statistically significant at the .0001 level. For reading speeds, mixed-case words were read more slowly than capitals $[F(1,25)=76.99$, $p<.0001]$, degraded words were read more slowly than intact $[F(1,25)=58.28, p<.0001]$, and the interaction of letter case and degradation was reliable $[F(1,25)=$ $23.03, p<.0001]$. Significantly more errors occurred for words in mixed case than those in capitals $[F(1,25)$ $=30.61, p<.0001]$, and degraded conditions caused more errors than intact $[F(1,25)=23.60, p<.0001]$. Finally, the interaction of letter case and stimulus degradation was also significant for error scores $[F(1,25)=$ $14.90, p<.0001]$.

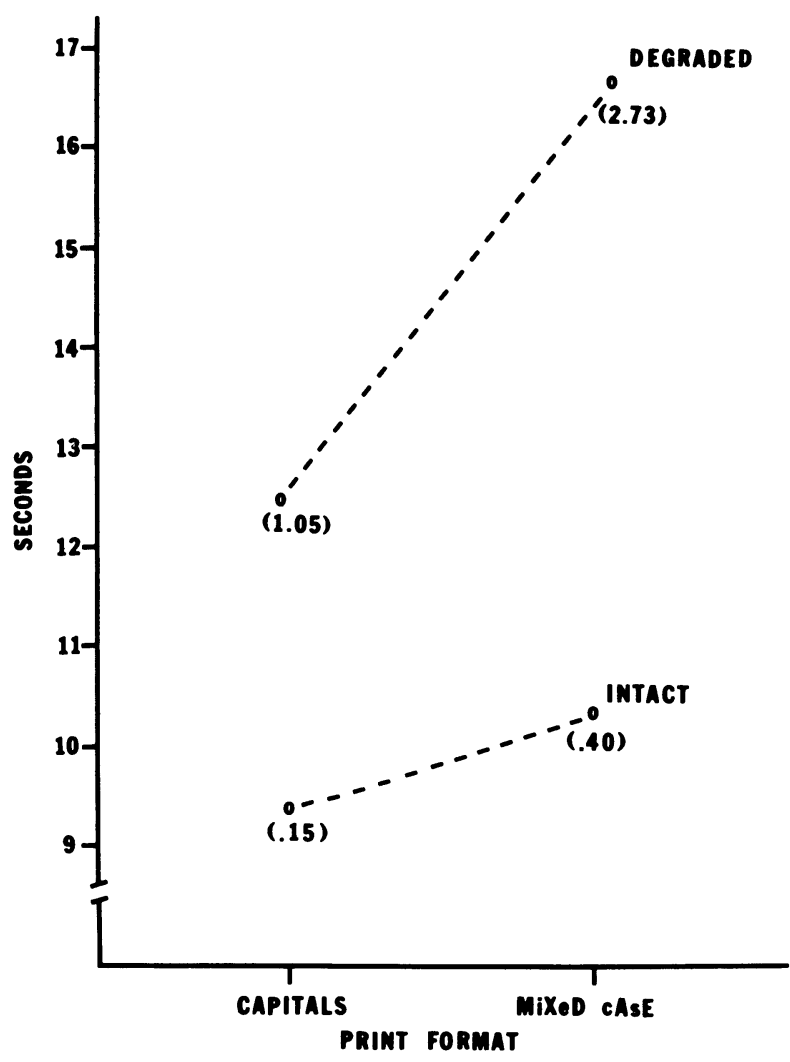

Figure 1. List pronunciation time (in seconds) for words printed in capitals versus mixed case at two levels of visual quality. Errors are given in parentheses.

\section{DISCUSSION}

The data show strong support for the hypothesis that letter case and stimulus degradation conditions each affect both reading speed and reading errors and that for both dependent variable measures, the effects of the two manipulations interact in an overadditive manner (i.e., each independent variable caused a change in reading time, and the combined effects of the two manipulations was greater than an additive relationship). Similarly, the two manipulations produced a hyperadditive effect on errors.

As noted, Sanders $(1980,1983)$ postulated a feature-extraction stage of symbol recognition that follows preprocessing and precedes identification. The present data suggest that the letter case and degradation conditions each affect Sanders's, hypothetical feature-extraction stage. Apparently, both manipulations have the effect of slowing the extraction of simple lines, angles, and curves prior to letter and word identification (see Gibson, 1969; Neisser, 1967).

The reader is cautioned that additive factor logic is not absolute. Many writers have criticized the method and have offered alternatives (e.g., McClelland, 1979; Taylor, 1976). Nonetheless, we find the conclusions based on Sanders's $(1980,1983)$ models plausible and consistent with prior research (e.g., Coltheart \& Freeman, 1974; Fisher, 1975; Sergent, 1984). Future research should be directed to broader representation and identification of stages and stage variables.

One of the most promising extensions of stage model research concerns the effects of acute drug dose applications in human information processing (for reviews, see Frowein, 1981; Sanders, 1980). Drugs such as alcohol, barbiturates, and amphetamines are frequently very selective in terms of the task variables with which they interact. For example, alcohol tends to interact only with stimulus-response compatibility variables (Tharp, Williams, Rundell, \& Lester, 1974), and is hence associated with the response-selection stage of processing. Secobarbital tends to interact only with masking, and hence has been associated 
with the feature-extraction stage (e.g., Logsdon, Hochhaus, Williams, Rundell, \& Maxwell, 1984). Based on such drug research, a logical prediction based on the present experiment is that the mixed-case variable would also interact with barbiturate treatment. Other similar generalizations, such as additivity between mixed-case manipulation and stimulus intensity or contrast (see Everett, Hochhaus, \& Brown, 1985), are also implied by the present results.

\section{REFERENCES}

Coltheart, M., \& Freeman, R. (1974). Case alternation impairs word identification. Bulletin of the Psychonomic Society, 3, 102-104.

Donders, F. C. (1969). [On the speed of mental processes.] In W. G. Koster (Ed. and Trans.), Attention and performance II. Amsterdam: North-Holland, 1969. (Reprinted from Acta Psychologica, 1969, 30; original work published 1868)

ERIKSEN, C. W., \& SchUltz, D. W. (1979). Information processing in visual search. Perception \& Psychophysics, 25, 249-263.

EVERETT, B. L., HochHAUS, L., \& BROWN, J. R. (1985). Letter-naming as a function of intensity, degradation, S-R compatibility, and practice. Perception \& Psychophysics, 37, 467-470.

Fisher, D. F. (1975). Reading and visual search. Memory \& Cognition, 3, 188-196.

FroweIN, H. W. (1981). Selective drug effects on human information processing. Soesterberg, The Netherlands: Institute for Perception TNO.

GiBson, E. J. (1969). Principles of perceptual learning and development. New York: Prentice-Hall.

KuCERA, H., \& Francis, W. N. (1967). Computational analysis of present-day American English. Providence, RI: Brown University Press.

LogSdon, R. L., Hochhaus, L., Williams, H. L., Rundell, O. H., \& MAXwELl, D. (1984). Secobarbital and perceptual processes. Acta Psychologica, 55, 179-193.

McClelland, D. (1979). On the time relations of mental processes: An examination of systems of processes in cascade. Psychological Bulletin, 86, 287-330.
Neisser, U. (1967). Cognitive psychology. Englewood Cliffs, NJ: Prentice-Hall.

PaChella, R. G. (1974). The interpretation of reaction time in human information processing research. In B. H. Kantowitz (Ed.), Human information processing: Tutorials in performance and cognition (pp. 41-81). Hillsdale, NJ: Erlbaum.

RozeN, P., \& JoNides, J. (1977). Mass reaction time: Measurement of the speed of the neural impulse and the duration of mental processes in class. Teaching of Psychology, 4, 91-94.

SAlthouse, T. A. (1981). Converging evidence for information processing stages: A comparative-influence stage analysis method. Acta Psychologica, 47, 39-61.

SANDERS, A. F. (1980). Stage analysis of reaction processes. In G. E. Stelmach \& J. Requin (Eds.), Tutorials in motor behavior (pp. 331354). Amsterdam: North-Holland.

SANDERS, A. F. (1983). Towards a model of stress and human performance. Acta Psychologica, 53, 61-97.

SCHWEIKERT, R. (1983). Latency network theory: Scheduling of processes in sentence verification and the Stroop effect. Journal of Experimental Psychology: Learning, Memory, \& Cognition, 9, 353-383.

SERGENT, J. (1984). Role of contrast, lettercase, and viewing conditions in a lateralized word-naming task. Perception \& Psychophysics, 35, 489-498.

Smith, E. E. (1968). Choice reaction time: An analysis of the major theoretical positions. Psychological Bulletin, 69, 77-110.

STERNBERG, S. (1969). On the discovery of processing stages: Some extensions of Donders' method. Acta Psychologica, 30, 276-315.

TAYLOR, D. A. (1976). Stage analysis of reaction time. Psychological Bulletin, 83, 161-191.

Tharp, V. K., Rundell, O. H., Lester, B. K., \& Williams, H. L. (1974). Alcohol and information processing. Psychopharmacologia, 40, 33-52.

(Manuscript received June 21, 1988.) 